\title{
Possibilities of transcatheter treatment of patients after extensive ischemic stroke
}

\author{
Ivan V. Maksimovich \\ Clinic of Cardiovascular Diseases named after Most Holy John Tobolsky, Moscow, Russia \\ Email: carvasc@yandex.ru
}

Received 20 April 2013; revised 28 May 2013; accepted 3 July 2013

Copyright (c) 2013 Ivan V. Maksimovich. This is an open access article distributed under the Creative Commons Attribution License, which permits unrestricted use, distribution, and reproduction in any medium, provided the original work is properly cited.

\begin{abstract}
The research investigates the efficacy of brain transcatheter laser revascularization in patients who have had extensive ischemic stroke. 1125 patients aged 29 81 (average age 75 ) with cerebral atherosclerosis were examined. The examination plan included: $C T$ brain scan, magnetic resonance imaging (MRI), brain scintigraphy (SG), rheoencephalography (REG), cerebral multi-gated angiography (MUGA), laboratory tests, assessment of severity of dementia (CDR), cognitive impairment (MMSE) and activities of daily living (IB). 93 patients suffered extensive ischemic stroke of whom 7 (7.53\%) had 10 - 15 IB points, 25 (26.88\%) -20 - 30 IB points, $61(65.59 \%)-35-45$ IB points. 69 patients underwent transcatheter treatment (Test Group). 24 patients underwent conservative treatment (Control Group). High-energy laser systems were used for revascularization of major intracranial arteries; lowenergy laser systems were used for revascularization of distal intracranial branches. Test Group: 67 (97.10\%) patients had good immediate angiographic outcome manifested in the restoration of lumen and patency of the affected vessels as well as in collateral revascularization. 12 - 24 months later the following positive trend was observed: $14(20.59 \%)$ patients demonstrated good clinical outcome (IB 90 - 100); 26 (38.24\%) patients had satisfactory clinical outcome (IB 75 - 85); $28(41.18 \%)$ patients showed relatively satisfactory clinical outcome (IB 60 - 70); relatively positive clinical outcome (IB < 60) was not obtained in any case. Control Group: 4 (16.67\%) patients showed relatively satisfactory clinical outcome (IB 60 - 70), relatively positive clinical outcome (IB $<60$ ) was achieved in 20 $(83.33 \%)$ cases. Evaluating the data obtained, it can be concluded that the method of transluminal laser revascularization of cerebral blood vessels is an effective one for the treatment of extensive ischemic strokes. The effect is maintained for a long time; it
\end{abstract}

causes regression of mental, intellectual and motor disorders, promotes regression of post-stroke dementia and significantly improves the quality of life, which makes it noticeably different from the conservative methods of treatment.

Keywords: Extensive Ischemic Stroke; Neurological Deficits; Post-Stroke Dementia; Transcatheter Treatment; Laser Revascularization

\section{INTRODUCTION}

Stroke is currently one of the most common pathological conditions both in neurological practice and in all clinical medicine. In many countries, it is one of the most common causes of death and severe disability of patients [1]. Thus, only in the US 800,000 strokes are registered each year [2]. About $30 \%$ of patients die in the acute phase, and this figure increases by $12 \%-15 \%$ in the next twelve months. The hardest to endure are macrofocal strokes associated with severe neurological deficit resulting in functional, motor, speech disorders, cognitive impairment and dementia [3-5]. An important role in the development of ischemic brain lesions is played by hypertension, hyperlipidemia, systemic hemodynamics disorders, microembolism caused by arrhythmia [6-9]. However, the main cause of the stroke is the atherosclerotic lesion of the vascular system of the brain [10].

The main part in the blood supply of brain cells is normally played by the capillary bed, and during developed ischemic process by the capillary and collateral channel which in its turn also has its own capillaries [11-13]. Large arterial trunks play a transportation role and only carry blood to the capillaries. The number of capillaries in 1 cubic centimeter of the brain tissue is 3 4 thousand [12]. Thus, the brain is the organ that requires the highest blood supply.

The brain tissue is extremely sensitive to blood supply disorders which quickly lead to the development of ische- 
mia and destructive processes. The more extensive the area of hypoperfusion is, the more it spreads to different parts of the brain, and the more severe the stroke is [1]. In this regard, any treatment of stroke, regardless of the terms of its development, should be directed in the first place to the restoration of the blood supply of the brain $[2,7,13]$.

If we ignore the intravenous thrombolysis in acute situations [14,15], conservative treatment of patients after extensive ischemic stroke is quite simple to carry out and therefore has a certain advantage, but it is mostly directed against the complications that develop as a result of the emerged cerebral ischemia [16]. Widespread atherosclerotic disease and serious cerebral hemodynamics disorders do not allow to significantly improve the cerebral blood flow by therapeutic methods.

Reconstructive vascular surgery has proved itself good on extracranial vessels [17]. However, it is quite difficult in patients with intracranial lesions due to certain anatomical features [18]. Surgery directed to create extraintracranial arterial anastomosis is not always effective in these patients, and the feasibility of such operations has been debated on all over the world for many years [19]. Transcatheter interventions such as balloon angioplasty and stenting of various kinds have as well proved themselves well in the extracranial parts of brachiocephalic branches [20], however, conducting such interventions presents certain difficulties with small diameters of intracranial arterial branches. Stenting can be performed only on the proximal parts of intracranial branches. It requires the use of stents of a small diameter and extremely miniature means of distal protection, while such operations often involve a fairly high risk of complications and stent thrombosis [21]. At the present stage of development of interventional neuroangiology the technique is impossible to be carried out on the distal parts of intracranial arteries.

Transcatheter interventions, such as intra-arterial thrombolysis or mechanical thrombectomy, are advisable only in the acute stage of the disease [22-25]. In this regard, there remains a need to develop new transcatheter treatments.

This research is dedicated to the possibility of restoration of cerebral blood supply in patients who have had extensive ischemic strokes spreading to different parts of the brain by means of the method of transcatheter laser revascularization. Also, the research investigates the possibility of reducing mental disorders and restoring mental and motor function in these patients in the short- and long-term periods.

\section{MATERIALS AND METHODS}

\subsection{Subject of Research}

All the studies and transcatheter procedures were per- formed with the approval of the Ethics Committee, as well as with the consent of the examined and treated patients and their relatives.

1125 patients aged 29 to 81 (average age 75) with different types of atherosclerotic lesions of the brain vessels were examined: 842 (74.84\%) males, 283 (25.16\%) females.

The examination plan included: CT scan of the brain (CT), magnetic resonance imaging (MRI), scintigraphy of the brain (SG), rheoencephalography (REG), cerebral multi-gated angiography (MUGA), laboratory tests, assessment of severity of dementia (CDR), cognitive impairment (MMSE) and activities of daily living (IB).

As we noted in our earlier work [13], all examined patients were divided into groups in accordance with the type of atherosclerotic lesions of brachiocephalic arterial branches:

- intracranial lesion type-501 (44.53\%);

- mixed type-519 (46.19\%);

- extracranial type-105 (9.33\%).

\subsection{Examination of Patients}

CT and MRI of the brain were performed on apparatus "Somatom" (Siemens), "HiSpeed" (GE), “Tomoscan" (Philips), "Apetro Eterna" (Hitachi) following the classical method.

SG of the brain, with the determination of the rate of cerebral blood flow, was carried out on a gamma camera (Ohio Nuclear, US) following the classical method in dynamic and static modes using the TC $99 \mathrm{M}$ pertechnetat 555 .

REG was conducted by means of "Reospektr-8" (Neurosoft, Russia) in accordance with the standard automated method determining pulse volume disorders in the hemispheres of the brain.

Primary CT, MRI, SG and REG were performed at the admission of the patients, repeated at the discharge of the patients, and then at intervals of 6 - 12 months.

MUGA of the brain was performed on apparatus "Advantx" (GE) following the classical method of transfemoral access. Simultaneously, taking into account the beginning and the speed of the injection, $10-12 \mathrm{ml}$ of Omnipack 350 was introduced intra-carotidally and 7 - 8 $\mathrm{ml}$ intra-vertebrally. The registration was carried out in front and side projections in constant subtraction mode at a speed of 25 frames per second. Further on the angiograms obtained in each phase of contrast enhancement were analyzed frame by frame [26]. Capillary density analysis was performed in the appropriate phase using an automatic method by means of the computer program "Angio Vision" based on determining the degree of blackening of the corresponding section of the brain tissue [27]. 
Laboratory tests were conducted according to generally accepted interventional cardiology schemes and included clinical, biochemical and coagulological examination.

The assessment of activities of daily living was performed using the Index Bartels Functional Evaluation: The Barthel Index (IB) [28]. Initial testing was performed during the admission of a patient; repeated testing was carried out on the day of their discharge, and then at intervals of 6 - 12 months.

If the patient's initial state allowed it, the assessment of the severity of dementia was conducted in accordance with J. C. Morris's 1993 classification (The Clinical Dementia Rating) [29]; the assessment of cognitive impairment was carried out by means of the Mini-Mental State Examination (MMSE) [30]. The initial testing was performed during the first examination of a patient or on the day of his/her hospitalization. Repeated testing was carried out on the day of the discharge of the patient, and then at intervals of 6 - 12 months.

\subsection{Selection of Patients}

Criteria for selection of patients for this research:

1) consent of the patient and his relatives for the examination and treatment;

2) medical condition of patients allowing the examination and treatment;

3) the presence of a macrofocal postischemic cyst extending to different parts of the brain;

4) the presence of predominant atherosclerotic lesion of intracranial arterial branches;

5) the time of treatment after a stroke in the period of 1 month to 6 years.

93 patients who had had extensive ischemic strokes were selected.

Test Group: 69 (74.19\%) patients aged 32 to 72 (average age 66), 51 (73.91\%) males and 18 (26.09\%) females.

Control Group: 24 (26.09\%) patients aged 45 to 78 (average age 68), 15 (62.50\%) males and 9 (37.50\%) females. The control group consisted of patients to whom transcatheter treatment either was not recommended or they and their families did not want to undergo it.

\subsection{Analysis of Patients}

According to the examination, the selected patients had the following:

- extensive postischemic brain cysts extending to different parts of the brain were found in 93 (100\%) cases;

- the deposition of calcium in the walls of cerebral blood vessels was detected in all 93 (100\%) cases;

- general involutive changes of the cerebral cortex ac- companied by an extension of the subarachnoid space were found in all 93 (100\%) cases;

- expanding of the Sylvian fissure was found in all 93 (100\%) cases;

- reduction in the intensity of the borders of the grey and white matter of the brain was found in 91 (97.85\%) cases;

- the signs of unocclusive hydrocephalus were found in 92 (98.92\%) cases;

- the slowing of blood flow in the cerebral hemispheres was observed in all 93 (100\%) cases;

- reduction of the pulse volume blood supply in the carotid and vertebrobasilar systems was detected in all 93 (100\%) cases;

- occlusal and stenotic atherosclerotic lesions in the basin of the front, middle, or posterior cerebral arteries on the side of the stroke were found in all 93 (100\%) cases. Stenotic atherosclerotic lesions of the intracranial branches on the contralateral side were detected in 91 (97.85\%) cases. Simultaneous moderate atherosclerotic lesions of the extracranial arteries not exceeding stenosis by $15 \%$ - 20\% (mixed type of lesion) were detected in 34 (36.56\%) cases;

- $\quad$ increased blood lipid level was detected in 86 (92.47\%) cases;

- hypercoagulability was detected in 76 (81.72\%) cases;

- reduction of activities of daily living (IB) was detected in all 93 (100\%) patients:

In assessing the activities of daily living:

- 10 - 15 IB points: 7 (7.53\%) patients including 5 Test Group patients and 2 Control Group patients;

- 20 - 30 IB points: 25 (26.88\%) patients including 15 Test Group patients and 10 Control Group patients;

- 35 - 45 IB points: 61 (65.59\%) patients including 49 Test Group patients and 12 Control Group patients.

The initial severity of dementia and the severity of cognitive impairment were identified in 33 (35.48\%) cases:

- moderate dementia (CDR-2) was detected in 18 (54.55\%) cases (11 - 18 MMSE points) including 17 Test Group patients and 1 Control Group patient;

- severe dementia (CDR-3) was detected in 15 (45.45\%) cases (7 - 10 MMSE points) including 9 Test Group patients and 6 Control Group patients.

Test Group. Given the small diameter of the affected intracranial arteries, for the revascularization of the brain in the Test Group we used the method of transluminal laser revascularization $[26,27,31]$ which allows to work on small diameter vessels. The efficacy and safety of this method had been proved in earlier experimental and clinical studies [13,31-35].

\section{The Method of Transcatheter Laser Revascularization of Cerebral Vessels}

To conduct the revascularization of the major intracranial 
arteries high-energy impulse laser systems were used; for the revascularization of the distal intracranial branches low-energy continuous laser systems were used [13,26,27].

The essence of the method is as following:

Under local anesthesia, according to Seldinger's classical method, the common femoral artery is punctured and catheterized with an installation of an introducer with a diameter of 6 - 9 F. Through this introducer and through coaxially brought guiding catheters installed in the general and further on in the internal carotid or in the vertebral artery, is brought a flexible fiber-optic instrument with a diameter of 50 to 200 micrometers, coupled with the laser unit. The fiber-optic instrument is guided to the site of intracerebral arteries lesion, after which the laser treatment is carried out. The distal end of the fiber-optic instrument is constantly washed with heparinized saline solution. Given the specificity of laser exposure on atherosclerotic tissue and the vascular wall $[26,35]$, the use of distal protection is not required. To carry out Xray control, small doses of radiopaque substance are periodically introduced. The exposure time depends on the nature of the atherosclerotic lesion, the type of the laser system used, and is from 30 seconds to 40 minutes. After the endovascular intervention the patient undergoes repeated cerebral multi-gated angiography following the procedure described above, the results of which determine the degree of revascularization and restoration of the cerebral vascular bed $[27,35]$. We assume that if the cerebral blood flow is not fully restored during the first attempt of the intervention, the manipulation can be repeated, but it was not necessary during the transcatheter interventions described.

Atherosclerosis is a systemic disease, and cerebral vascular lesion develops in all the basins, not just in the stroke-dependant artery. In order to improve the blood supply of the whole brain, as well as with a view to the revascularization of the affected hemisphere by collateral blood supply of the contralateral vascular basin, transcatheter interventions were usually carried out from two sides.

Postoperative treatment was carried out by common interventional neuroangiology schemes and dosing. The patients underwent conventional desagrigant, anticoagulant, vasodilator and nootropic therapy including Aspirin, Heparin, indirect anticoagulants (depending on the blood coagulation indicators), Pentoxifylline $100 \mathrm{mg}$, Complamin 150 mg, Inosin 200 mg, Nootropil (Piracetam) 1200 mg (or Gliatilin $1000 \mathrm{mg}$ ) intravenously, drop by drop, No. 10 - 15; and then they took tablets. Subsequent 3-months courses of tablets were repeated twice a year.

Control Group. Control Group patients underwent a therapeutic treatment following similar schemes and doses of the drugs. In the aftermath, they also took 3 months courses of tablets twice a year.

\subsection{Rehabilitation of Patients}

To carry out rehabilitation programs to restore motor function, the patients were sent to other hospitals after the treatment.

\subsection{Evaluation}

As activities of daily living (IB) were the only aspect that could be determined in 100\% of the treated patients at their admission, a long-term clinical outcome was evaluated as follows:

- A good clinical outcome after the treatment was considered to be an almost complete restoration of motor function, mental abilities, with the restoration of activities of daily living to 90 - 100 IB points.

- A satisfactory clinical outcome was considered to be an incomplete restoration of motor function, mental abilities, with the restoration of activities of daily living to 75 - 85 IB points.

- A relatively satisfactory clinical outcome was considered to be a partial restoration of motor function, mental abilities, with the restoration of activities of daily living to 60 - 70 IB points.

- A relatively positive clinical outcome was considered to be the absence of negative dynamics with an insignificant restoration of motor functions, intellectual abilities, with the level of activities of daily living below 60 IB points.

\section{RESULTS}

\subsection{Test Group}

\subsubsection{Immediate Results}

A good immediate intraoperative angiographic outcome manifested in the restoration of the lumen and patency of the affected vessels, as well as in marked collateral revascularization of the brain on the affected side, was obtained in 67 (97.10\%) cases. Improved blood supply in the contralateral hemisphere was obtained in 69 (100\%) cases. Improved blood supply in the affected hemisphere by means of the collateral revascularization from contralateral vascular basins was obtained in 68 (98.55\%) cases (One patient died in the early postoperative period because of the reasons unrelated to the treatment performed, and therefore he has not been included in the further statistics).

\subsubsection{Results According to SG and REG Data}

According to SG data, improved blood flow in the cerebral hemispheres, both on the affected and the contralateral side, was observed in all $68(100 \%)$ cases, and the positive trend was being detected during the whole observation period.

According to REG data, improved pulse-volume blood 
flow in the carotid and vertebrobasilar basins in the affected and contralateral sides was found in all 68 (100\%) cases, and the positive trend was being detected during the whole observation period.

\subsubsection{Results According to $C T$ and MRI Data}

According to CT and MRI data, in the first 12 - 24 months after the treatment a reduction of the postischemic cyst size by $10 \%$ - $15 \%$ was observed in 37 (54.41\%) cases, by $15 \%-25 \%$-in 23 (33.82\%) cases, by more than $25 \%$ -in $8(11.76 \%)$ cases.

It should be noted that in the period of observation that followed, there remained a trend towards the reduction in the postischemic cyst size, as well as towards the signs of cerebral tissue restoration.

\subsubsection{Clinical Results}

The clinical results assessment was conducted at various times after the transcatheter interference.

The restoration of mental, verbal and motor functions depended to a large extent on the severity of the initial disorders, on the location and size of the ischemic part of the brain and on the timing of transcatheter intervention after the stroke.

It should be noted that the restoration of mental abilities proceeded much faster than the one of motor functions, which is associated with the developed secondary disorders of the peripheral nervous and musculoskeletal functions requiring long term treatment in their turn.

The initial positive trend was observed quite soon after the transcatheter treatment. In the early stages - the first 2 - 3 weeks - the conducted treatment allowed to improve all the patients' condition, reduce mental and motor disorders.

In the long-term period, the conducted treatment allowed to significantly improve mental and motor function, and to recover them in a number of patients, which in turn led to the restoration of activities of everyday living, as well as to transfer some patients into the category of patients without dementia and cognitive impairment.

According to IB data, the treated patients showed the following clinical outcome in 12 - 24 months:

- a good clinical outcome was obtained in 14 (20.59\%) cases;

- a satisfactory clinical outcome was obtained in 26 (38.24\%) cases;

- a relatively satisfactory clinical outcome was obtained in 28 (41.18\%) cases;

- a relatively positive clinical outcome was not obtained in any case.

No negative result was obtained after the treatment.

In the longer term, the obtained positive trend remained and progressed.
Statistical analysis of the data is presented in Table $\mathbf{1 .}$

26 Test Group patients, whose severity of dementia and of cognitive impairment had been determined before the treatment, showed the following positive trend in 12 24 months:

- No signs of dementia; the restoration of cognitive functions to 27 - 30 MMSE points-5 (19.23\%) cases;

- The reduction of the severity of dementia to CDR-1; the restoration of cognitive functions to $21-26$ MMSE points-15 (57.69\%) cases;

- The reduction of the severity of dementia to CDR-2; the restoration of cognitive functions to $17-20$ MMSE points-6 (23.08\%) cases.

In the longer term, there was no regression of the received positive trend.

\subsubsection{Treatment Examples}

The following are some examples:

Patient S., male, 57 years old, had suffered a massive stroke in the right hemisphere resulting in developed leftsided hemiparesis and incomplete sensory-motor aphasia. 12 months after the stroke: the severity of dementiaCDR-3, cognitive impairment-10 MMSE points, the level of activities of everyday life-40 IB points. CT of the brain revealed an extensive postischemic cyst of the right hemisphere extending to the frontal and parietal regions (Figure 1) of $7.5 \times 4.8 \times 6.2 \mathrm{~cm}$.

During SG and REG there was a marked reduction of blood flow and pulse-blood volume with the domination of the process in the right. Cerebral MUGA revealed a subtotal stenosis of the distal part of the trunk of the right internal carotid artery (Figure 2).

The patient underwent transcatheter laser revascularization first of the right and then of the left hemisphere. Postoperative cerebral MUGA revealed: patency and lumen of the distal part of the right internal carotid artery are completely restored (Figure 3); marked collateral revascularization.

SG and REG in the postoperative period showed the positive dynamics of blood flow and pulse blood volume in the cerebral hemispheres.

3 months later there was a restoration of motor functions, intellectual abilities and professional skills. The severity of dementia decreased to CDR-1, MMSE-25 points, IB-85 points; the patient returned to his work.

12 months after the treatment there were no signs of dementia, MMSE-28 points, IB-100 points. Repeated CT of the brain revealed a decrease in the size of the postischemic cyst with the symptoms of the restoration of the structure of cerebral tissue (Figure 4).

5 years after the transcatheter treatment cerebral MUGA (Figure 5) revealed: the lumen and patency of the right internal carotid artery are completely preserved and there is further progression of collateral revascularization. 
Table 1. Comparison of the clinical outcome obtained in test and control group patients after the treatment.

\begin{tabular}{|c|c|c|c|c|c|c|}
\hline GROUP & & $\begin{array}{c}\text { After treatment } \\
I B=60-70\end{array}$ & $\begin{array}{l}\text { After treatment } \\
\text { IB }=75-85\end{array}$ & $\begin{array}{c}\text { After treatment } \\
\text { IB }=90-100\end{array}$ & $\begin{array}{c}\text { After treatment } \\
\text { IB }=<60\end{array}$ & Totals \\
\hline $\begin{array}{c}\text { Test Group: } \\
\text { Number of Patients }\end{array}$ & $\begin{array}{l}\text { Before treatment } \\
\text { IB }=10-15\end{array}$ & 3 & 1 & $\mathbf{0}$ & $\mathbf{0}$ & 4 \\
\hline Column Percentage & & $10.71 \%$ & $3.85 \%$ & $0.00 \%$ & $0.00 \%$ & \\
\hline Row Percentage & & $75.00 \%$ & $25.00 \%$ & $0.00 \%$ & $0.00 \%$ & \\
\hline Sample Proportion & & $4.41 \%$ & $1.47 \%$ & $0.00 \%$ & $0.00 \%$ & $5.88 \%$ \\
\hline $\begin{array}{c}\text { Test Group: } \\
\text { Number of Patients }\end{array}$ & $\begin{array}{c}\text { Before treatment } \\
\text { IB }=\mathbf{2 0}-\mathbf{3 0}\end{array}$ & 7 & 6 & 2 & $\mathbf{0}$ & 15 \\
\hline Column Percentage & & $25.00 \%$ & $23.08 \%$ & $14.29 \%$ & $0.00 \%$ & \\
\hline Row Percentage & & $46.67 \%$ & $40.00 \%$ & $13.33 \%$ & $0.00 \%$ & \\
\hline Sample Proportion & & $10.29 \%$ & $8.82 \%$ & $2.94 \%$ & $0.00 \%$ & $22.05 \%$ \\
\hline $\begin{array}{c}\text { Test Group: } \\
\text { Number of Patients }\end{array}$ & $\begin{array}{c}\text { Before treatment } \\
\quad I B=35-45\end{array}$ & 18 & 19 & 12 & $\mathbf{0}$ & 49 \\
\hline Column Percentage & & $64.29 \%$ & $73.08 \%$ & $85.71 \%$ & $0.00 \%$ & \\
\hline Row Percentage & & $36.73 \%$ & $38.78 \%$ & $24.49 \%$ & $0.00 \%$ & \\
\hline Sample Proportion & & $26.47 \%$ & $27.94 \%$ & $17.65 \%$ & $0.00 \%$ & $72.06 \%$ \\
\hline TOTALS of Test Group & & 28 & 26 & 14 & $\mathbf{0}$ & 68 \\
\hline Sample Proportion & & $41.18 \%$ & $38.24 \%$ & $20.59 \%$ & $0.00 \%$ & $100.00 \%$ \\
\hline $\begin{array}{l}\text { Control Group: } \\
\text { Number of Patients }\end{array}$ & $\begin{array}{c}\text { Before treatment } \\
I B=10-15\end{array}$ & $\mathbf{0}$ & $\mathbf{0}$ & $\mathbf{0}$ & 2 & 2 \\
\hline Column Percentage & & $0.00 \%$ & $0.00 \%$ & $0.00 \%$ & $10.00 \%$ & \\
\hline Row Percentage & & $0.00 \%$ & $0.00 \%$ & $0.00 \%$ & $100.00 \%$ & \\
\hline Sample Proportion & & $0.00 \%$ & $0.00 \%$ & $0.00 \%$ & $8.33 \%$ & $8.33 \%$ \\
\hline $\begin{array}{l}\text { Control Group: } \\
\text { Number of Patients }\end{array}$ & $\begin{array}{c}\text { Before treatment } \\
\text { IB }=20-30\end{array}$ & 1 & 0 & 0 & 9 & 10 \\
\hline Column Percentage & & $25.00 \%$ & $0.00 \%$ & $0.00 \%$ & $45.00 \%$ & \\
\hline Row Percentage & & $10.00 \%$ & $0.00 \%$ & $0.00 \%$ & $90.00 \%$ & \\
\hline Sample Proportion & & $4.17 \%$ & $0.00 \%$ & $0.00 \%$ & $37.50 \%$ & $41.67 \%$ \\
\hline $\begin{array}{l}\text { Control Group: } \\
\text { Number of Patients }\end{array}$ & $\begin{array}{c}\text { Before treatment } \\
\text { IB }=35-45\end{array}$ & 3 & $\mathbf{0}$ & $\mathbf{0}$ & 9 & 12 \\
\hline Column Percentage & & $75.00 \%$ & $0.00 \%$ & $0.00 \%$ & $45.00 \%$ & \\
\hline Row Percentage & & $25.00 \%$ & $0.00 \%$ & $0.00 \%$ & $75.00 \%$ & \\
\hline Sample Proportion & & $12.50 \%$ & $0.00 \%$ & $0.00 \%$ & $37.50 \%$ & $50.00 \%$ \\
\hline \multirow[t]{2}{*}{ TOTALS of Control Group } & & 4 & $\mathbf{0}$ & $\mathbf{0}$ & 20 & 24 \\
\hline & & $16.67 \%$ & $0.00 \%$ & $0.00 \%$ & $83.33 \%$ & $100.00 \%$ \\
\hline Column Total & & 32 & 26 & 14 & 20 & 92 \\
\hline Percentage of Total & & $34.78 \%$ & $28.26 \%$ & $15.22 \%$ & $21.74 \%$ & $100.00 \%$ \\
\hline
\end{tabular}

The original data, the distribution of which is given in the summary table, were analyzed using the nonparametric Mann-Whitney test. The statistical analysis showed that at the beginning of the therapy there were no significant differences between the Test and Control Groups ( $p=0.12$ ), while after the treatment these differences became significant $(\mathrm{p}<0.01)$. The analysis of the indicator dynamics by means of the Mann-Whitney test also revealed significant differences between the groups: the effect of the therapy in the Test Group was significantly higher than in the Control Group ( $<<0.01$ ).

No clinical signs of dementia; the patient retired because of his age.

10 years after the transcatheter treatment MRI of the brain (Figure 6) demonstrated further regression of the postischemic cyst with the symptoms of the restoration of the structure of cerebral tissue.

At the same time MRI angiography showed that the lumen and patency of the right internal carotid artery are preserved, with good filling of the distal bed (Figures 7(a) and (b)).

Patient Z., male, 42 years old. Had suffered a massive stroke of the right hemisphere. In the first days after the onset of the stroke MRI angiography (Figure 8) revealed occlusion of the right middle cerebral artery.

6 months after the stroke there is left-sided hemipare- sis, incomplete sensory-motor aphasia, the severity of dementia-CDR-2, cognitive impairment-18 MMSE points, the level of activities of everyday living - 40 IB points. CT of the brain revealed an extensive postischemic cyst of the right hemisphere extending to the frontal and parietal regions, of $6.7 \times 2.7 \times 5.0 \mathrm{~cm}$ (Figure 9).

During SG and REG there was a marked reduction of blood flow and pulse blood volume with a domination of the process in the right.

Cerebral MUGA revealed occlusion of the right middle cerebral artery (Figure 10).

The patient underwent two-sided transcatheter laser revascularization. Postoperative cerebral MUGA (Figure 11) showed restoration of patency of the right middle cerebral artery, marked distal collateral revascularization. 


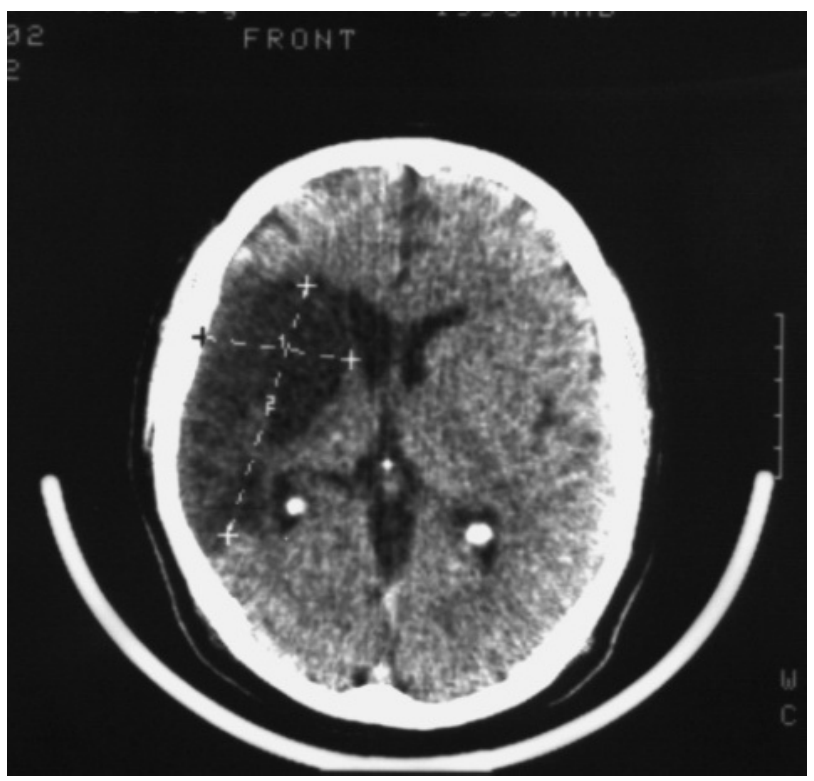

Figure 1. Example: Patient S. male, 57 years old (CDR-3): CT of the brain. BEFORE THE OPERATION: a huge postischemic cyst of $7.5 \times 4.8 \times 6.2 \mathrm{~cm}$ in the right middle cerebral artery region.

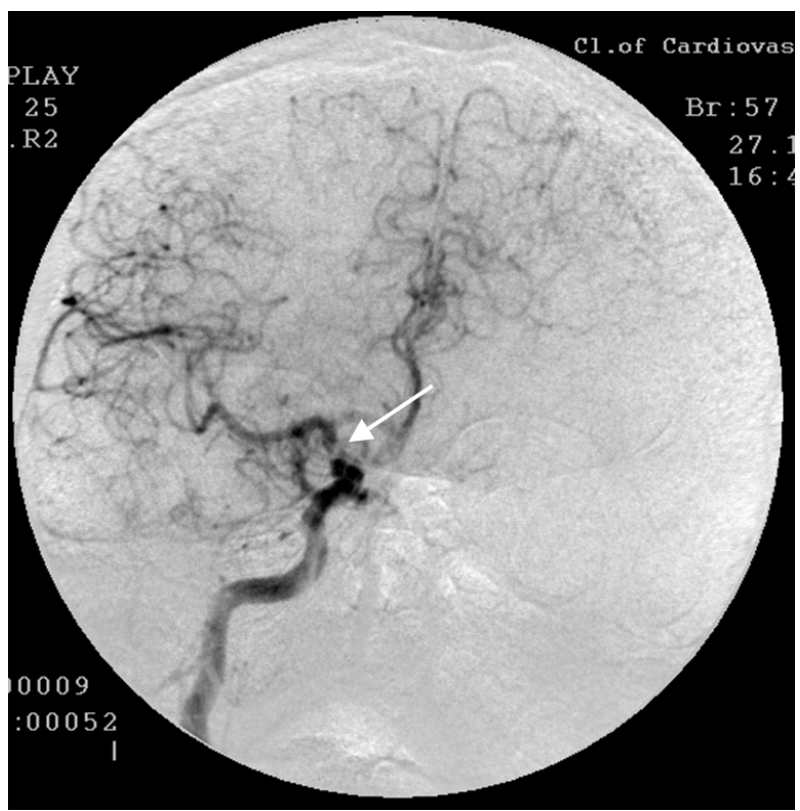

Figure 2. The same patient S.: right-sided carotid MUGA (front projection). BEFORE THE OPERATION: subtotal stenosis of the distal part of the trunk of the right internal carotid artery.

SG and REG showed positive dynamics of blood flow and pulse blood volume in the cerebral hemispheres. 3 months later the patient demonstrated improvement in motor functions and intellectual abilities, reduction of sensory-motor aphasia, the severity of dementia decreased to CDR-1.

12 months after the transcatheter treatment repeated

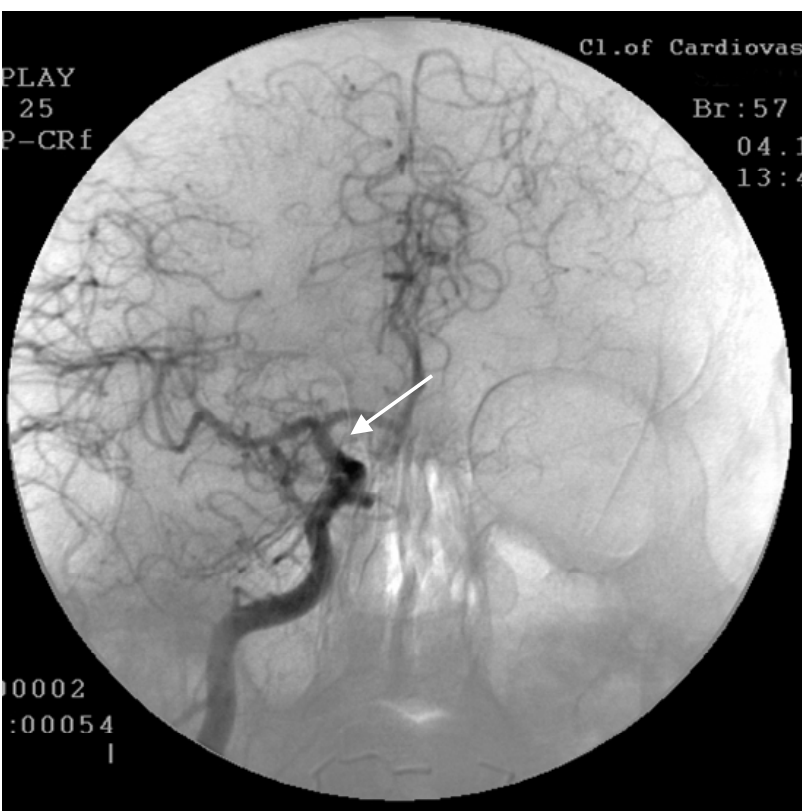

Figure 3. The same patient S.: right-sided carotid MUGA (front projection). AFTER THE OPERATION: complete restoration of the lumen and patency of the trunk of the right internal carotid artery.

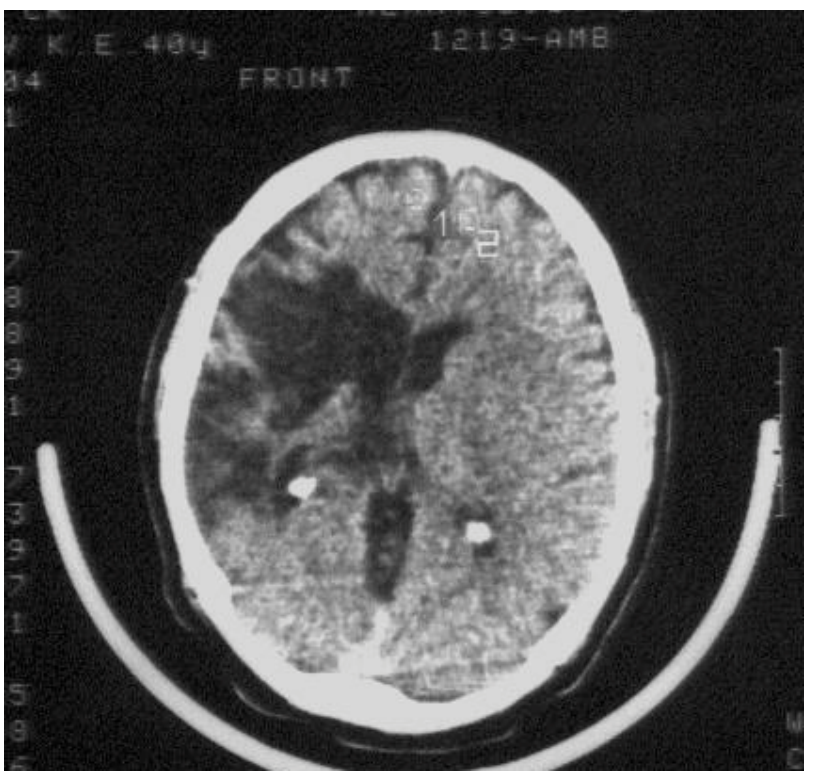

Figure 4. The same patient S.: CT of the brain 12 MONTHS AFTER LASER REVASCULARIZATION: significant decrease in the size of the postischemic cyst with the sings of brain tissue regeneration.

cerebral CT (Figure 12) showed a decrease in the size of the postischemic cyst with the symptoms of the restoration of the structure of cerebral tissue.

There are virtually no mental or motor disorders, no signs of dementia, IB-100 points. The patient returned to his previous intellectual work (he is an engineer).

10 years after the transcatheter treatment there are no 


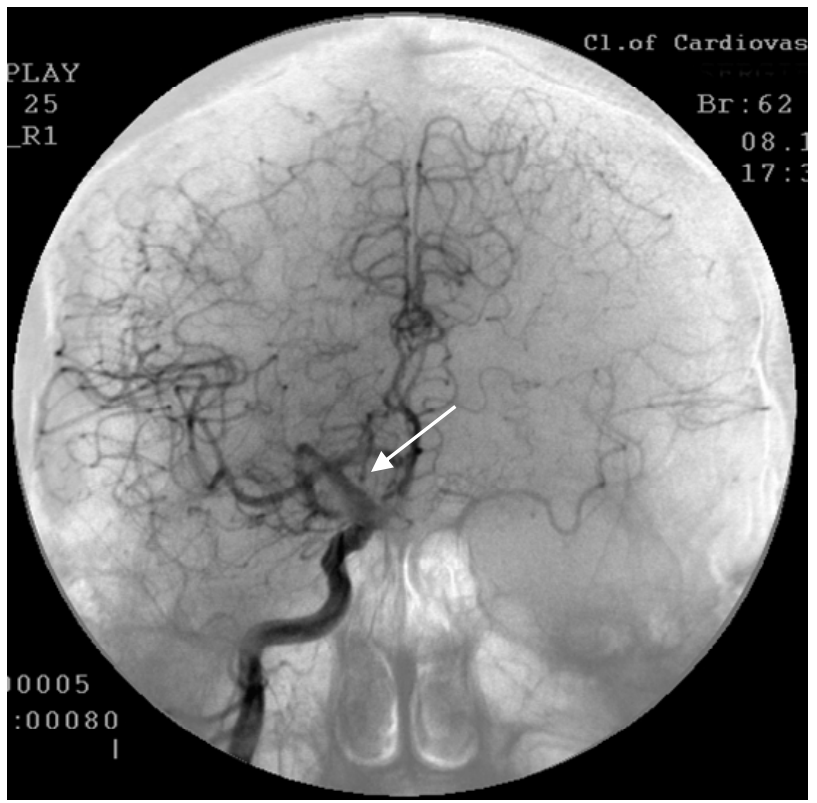

Figure 5. The same patient S.: right-sided carotid MUGA (front projection). 5 YEARS AFTER THE OPERATION: the lumen and patency of the middle cerebral artery trunk completely preserved, further progression of collateral revascularization.

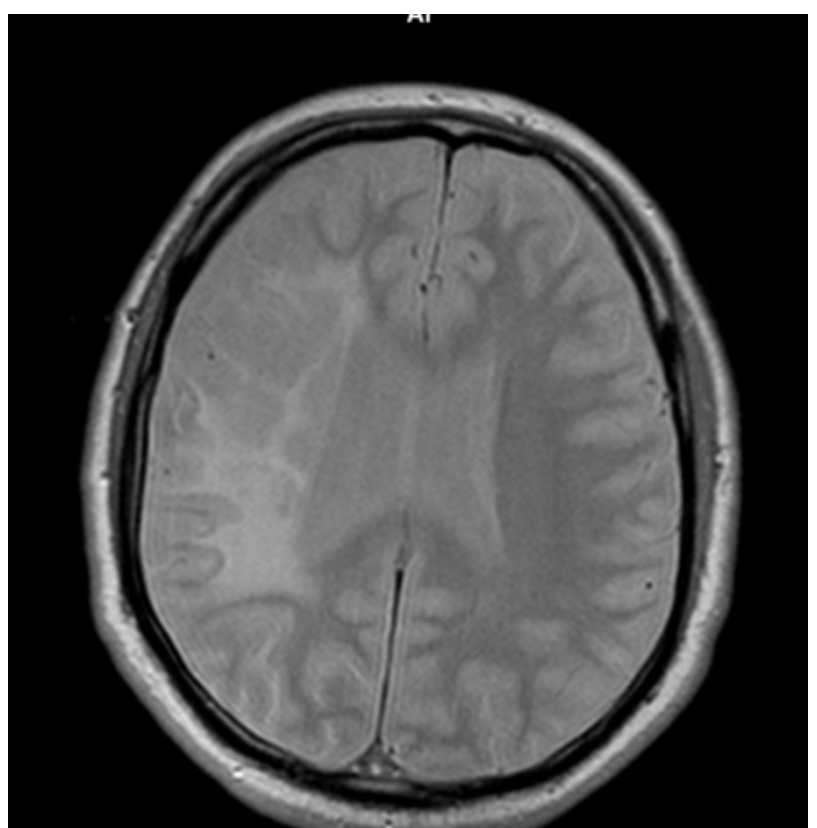

Figure 6. The same patient S.: MRI of the brain 10 YEARS AFTER THE TREATMENT: further regression of the postischemic cyst with the symptoms of the structure of cerebral tissue reconstruction.

signs of dementia, IB-100 points, the patient continues to successfully work as an engineer at the same place. Cerebral MRI indicates further regress of the postischemic cyst with the symptoms of the restoration of the structure of cerebral tissue. MRI angiography showed

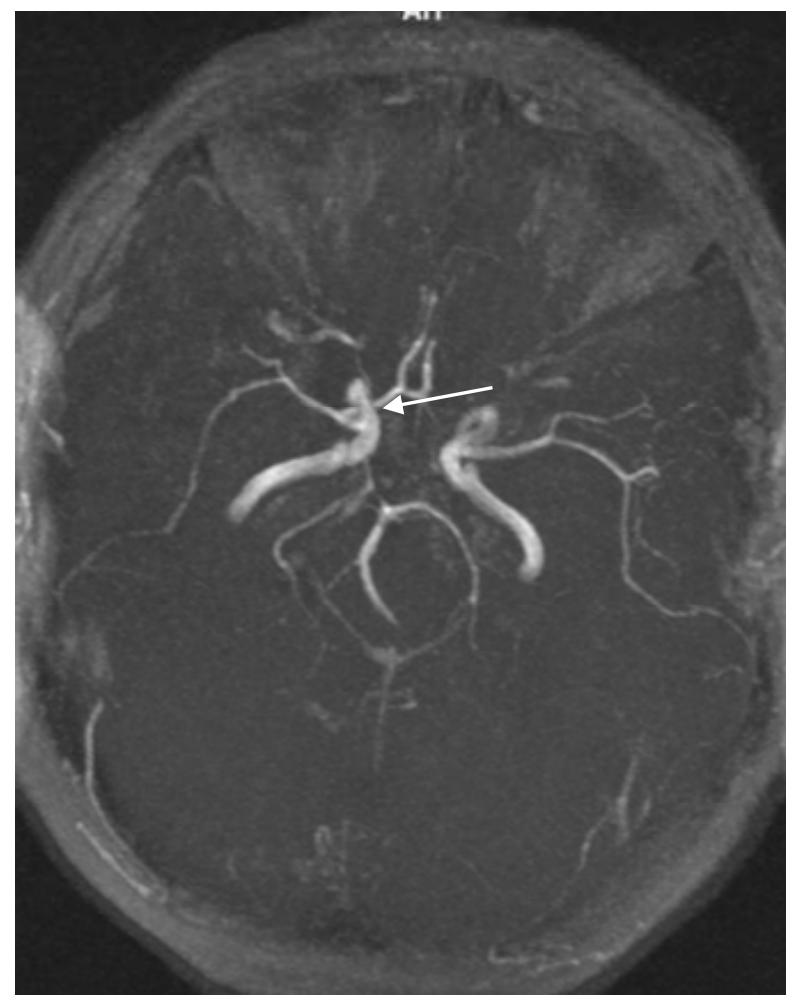

(a)

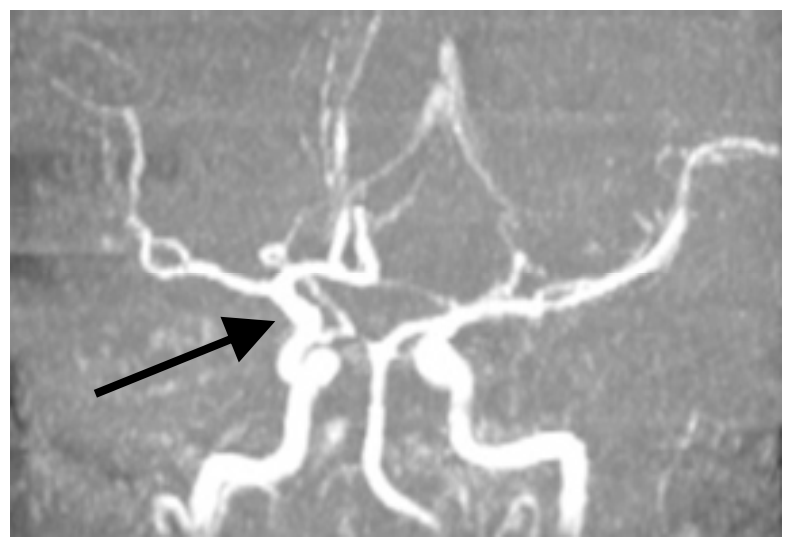

(b)

Figures 7. The same patient S.: MRI angiography of the brain 10 YEARS AFTER THE TREATMENT: the lumen and patency of the right internal carotid artery are preserved.

that the lumen and patency of the right internal carotid artery are preserved, with good filling of the distal bed (Figure 13).

Patient G., male, 56 years old. Had suffered a massive stroke of the left hemisphere. In the first days after the onset of the stroke CT of the brain revealed a forming extensive postischemic cyst of the left hemisphere (Figure 14).

1 month after the stroke onset there is confusion of consciousness, right-sided hemiparesis, sensory-motor aphasia; the severity of dementia and cognitive impair- 


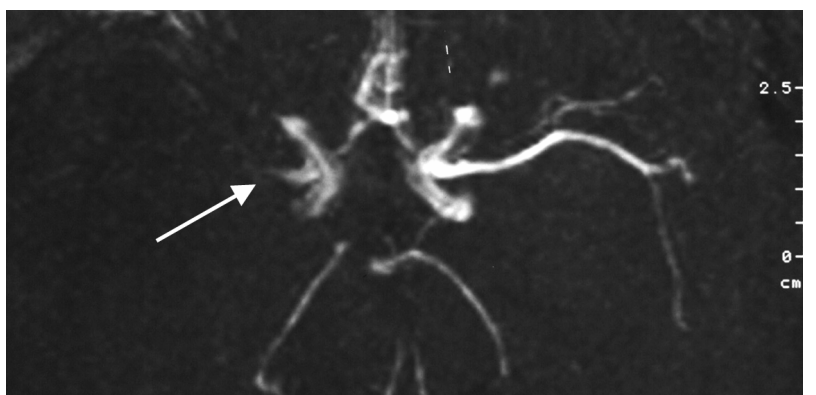

Figure 8. Example: Patient Z. male, 42 years old: MRI angiography. THE FIRST 24 HOURS AFTER THE STROKE ONSET: occlusion of the trunk of the right middle cerebral artery.

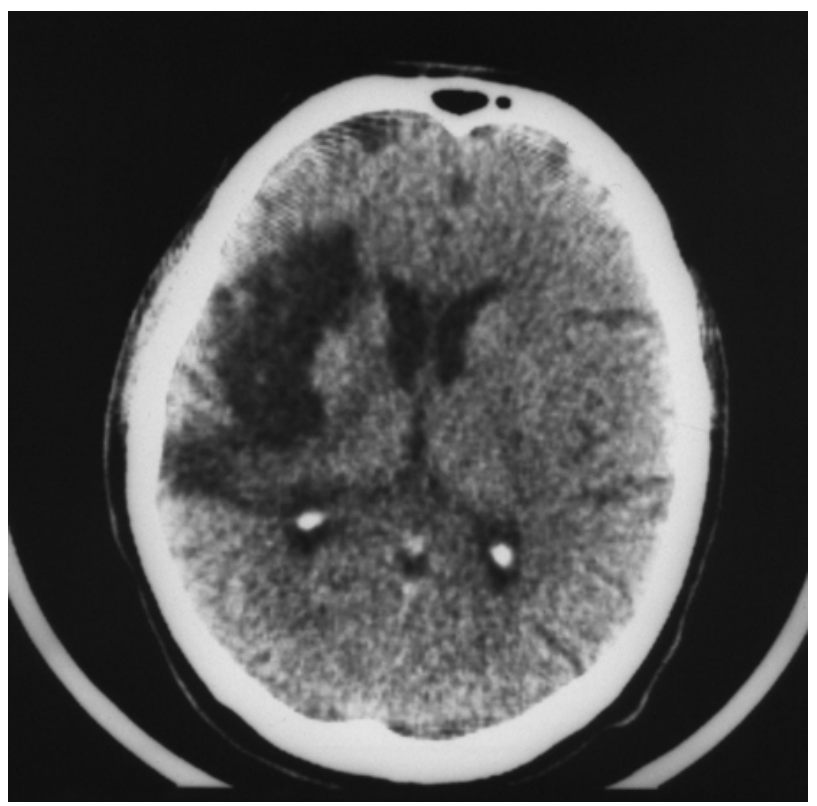

Figure 9. The same patient Z. (CDR-2): CT of the brain. BEFORE THE OPERATION: an extensive postischemic cyst of the right hemisphere extending to the frontal and parietal regions of $6.7 \times 2.7 \times 5.0 \mathrm{~cm}$.

ment can not be determined, IB-10 points. Repeated $\mathrm{CT}$ of the brain revealed an extensive postischemic cyst in the left hemisphere extending to the frontal, parietal, and occipital regions (Figure 15).

Cerebral MUGA revealed occlusion of the left anterior cerebral artery (Figure 16).

The patient underwent two-sided transcatheter laser revascularization; postoperative cerebral MUGA (Figure 17) showed restoration of the patency of the left anterior cerebral artery, marked collateral revascularization.

1 year after the transcatheter treatment cerebral CT (Figure 18) showed regress of the postischemic cyst with the symptoms of the restoration of the structure of cerebral tissue.

Right hemiplegia significantly regressed, sensory-motor aphasia decreased, but is partially preserved, the severity

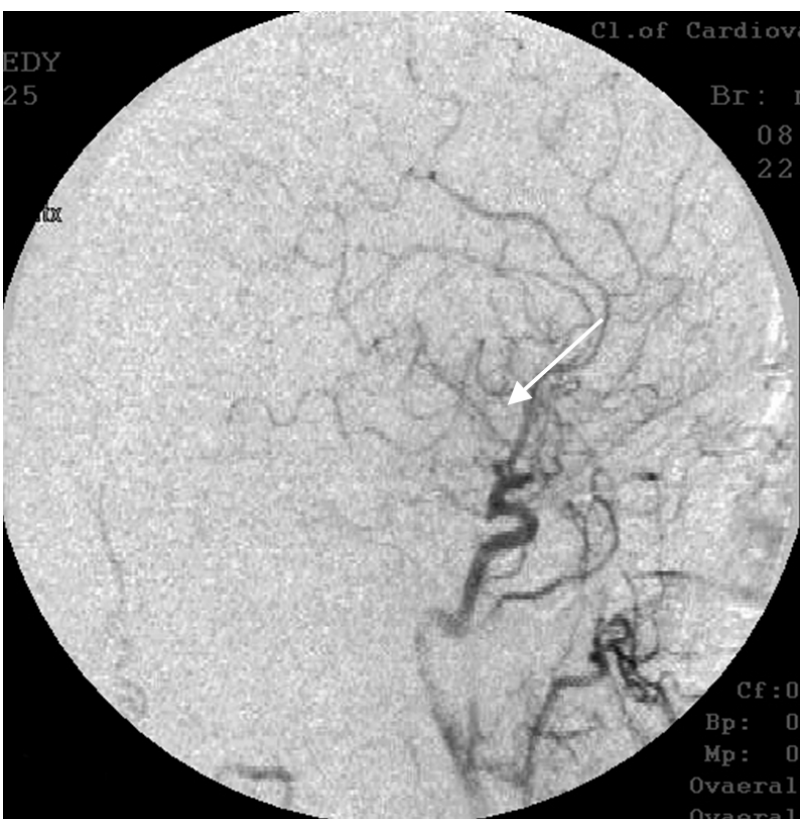

Figure 10. The same patient Z.: right-sided carotid MUGA (lateral projection). BEFORE THE OPERATION: occlusion of the right middle cerebral artery.

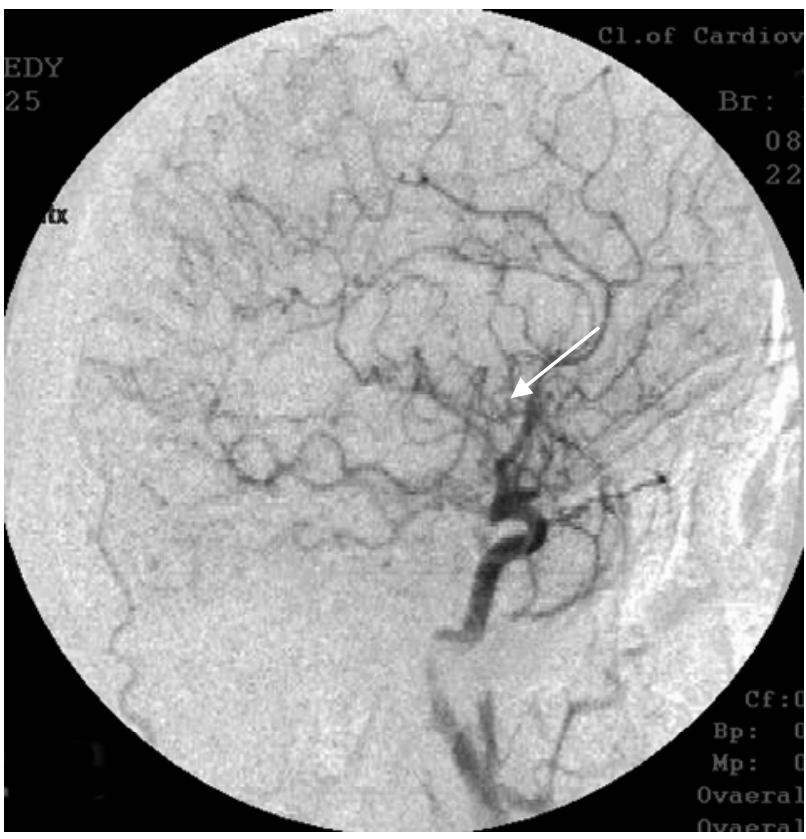

Figure 11. The same patient Z.: right-sided carotid MUGA (lateral projection). AFTER THE OPERATION: restoration of the right middle cerebral artery, marked collateral revascularization.

of dementia (including residual effects of motor and mental disorders) virtually corresponds to CDR-1, MMSE20 points, IB-80 points.

\subsubsection{Complications}

There was no embolism or thrombosis in the distal cere- 


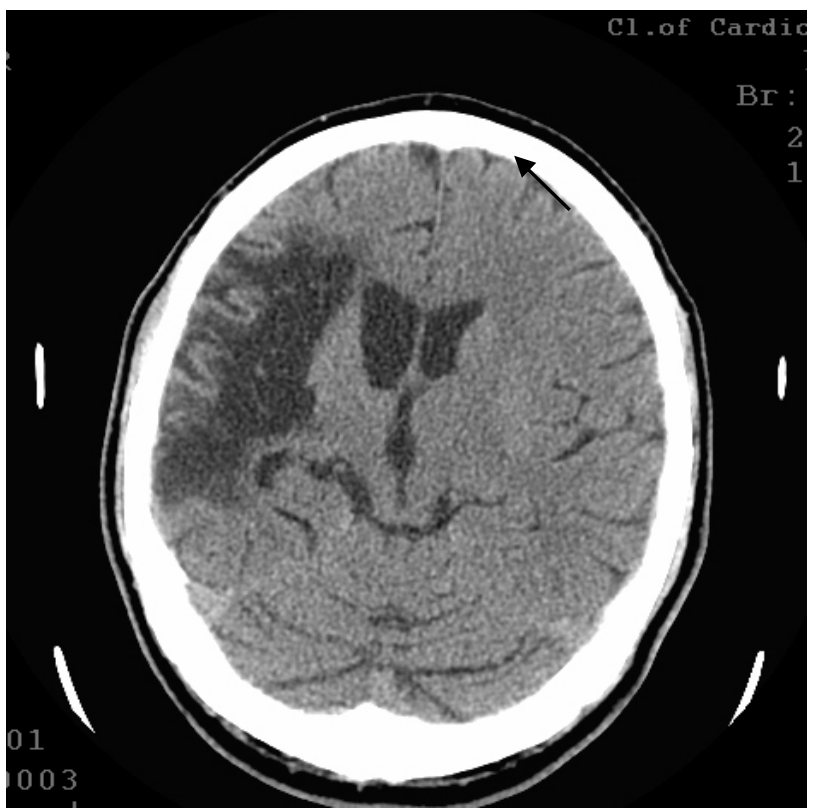

Figure 12. The same patient Z.: CT of the brain 12 MONTHS AFTER LASER REVASCULARIZATION: significant decrease in the size of the postischemic cyst with the sings of brain tissue regeneration.

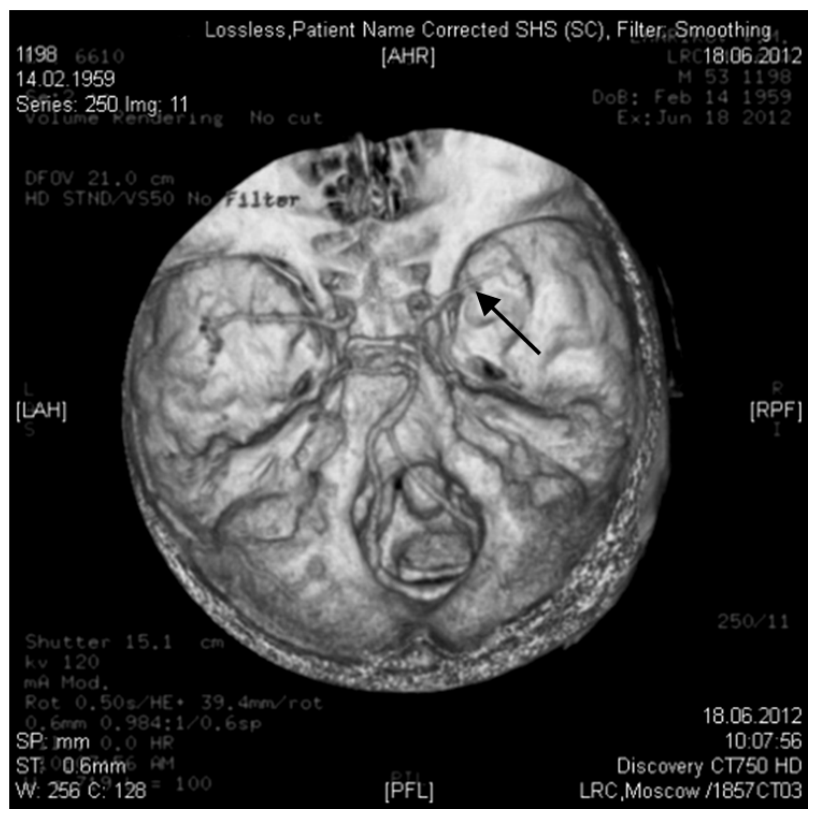

Figure 13. The same patient Z.: MRI angiography of the brain 10 YEARS AFTER THE TREATMENT: the lumen and patency of the right internal carotid artery are preserved.

bral arterial bed during the transcatheter treatment. There was no negative effect of the transluminal laser revascularization observed.

After the intervention, 2 patients developed minor hematomas at the puncture site of the femoral artery not requiring surgical treatment, but this is not a complication after the intervention applied.

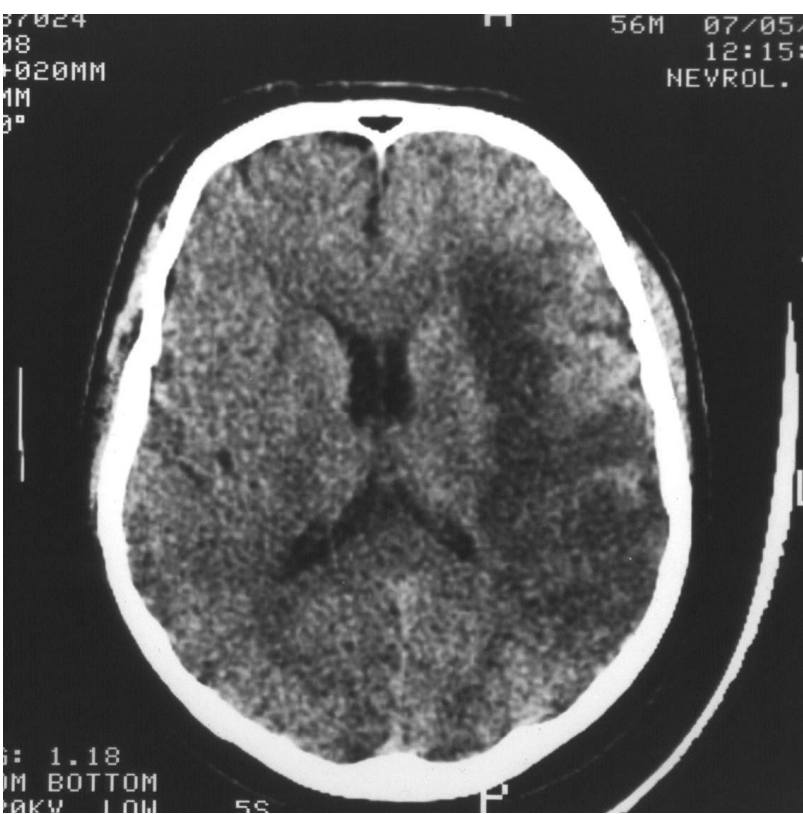

Figure 14. Example: Patient G. male, 56 years old: CT of the brain. 3 DAYS AFTER THE STROKE ONSET: forming extensive postischemic cyst of the left hemisphere.

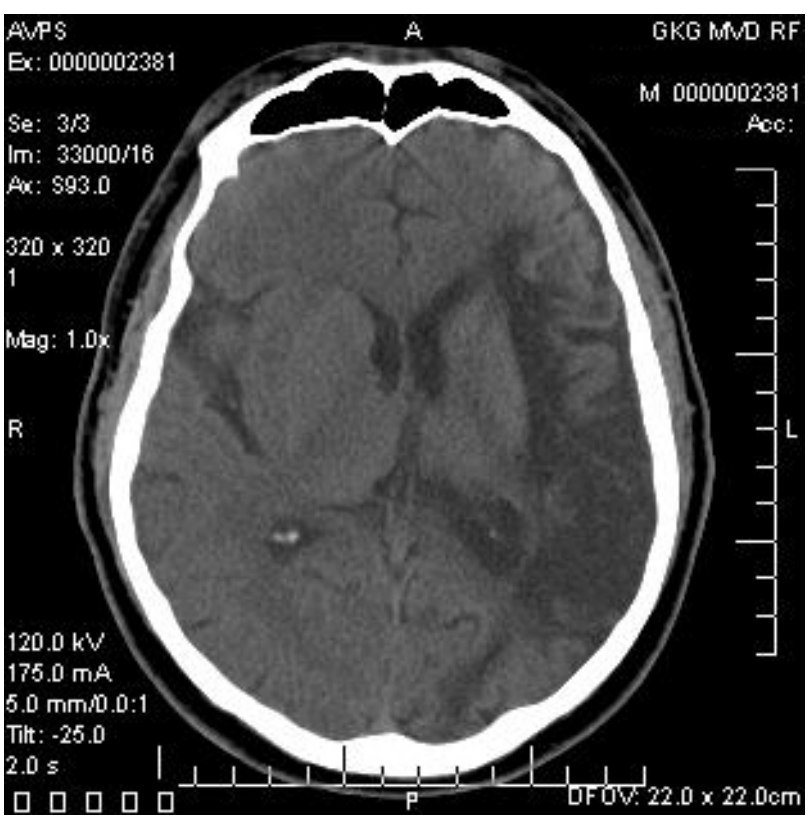

Figure 15. The same patient G.: CT of the brain. $1 \mathrm{MONTH}$ AFTER THE STROKE ONSET: an extensive postischemic cyst of the left hemisphere extending to frontal, parietal, and occipital regions.

One patient, being treated because of the categorical insistence of his relatives, had a large thrombosed postinfarction aneurysm of the left ventricle. Thrombotic masses embolism of this aneurysm was the cause of the first massive stroke of the left fronto-parietal region. Laser revascularization of the left hemisphere was successfully performed on this patient. 


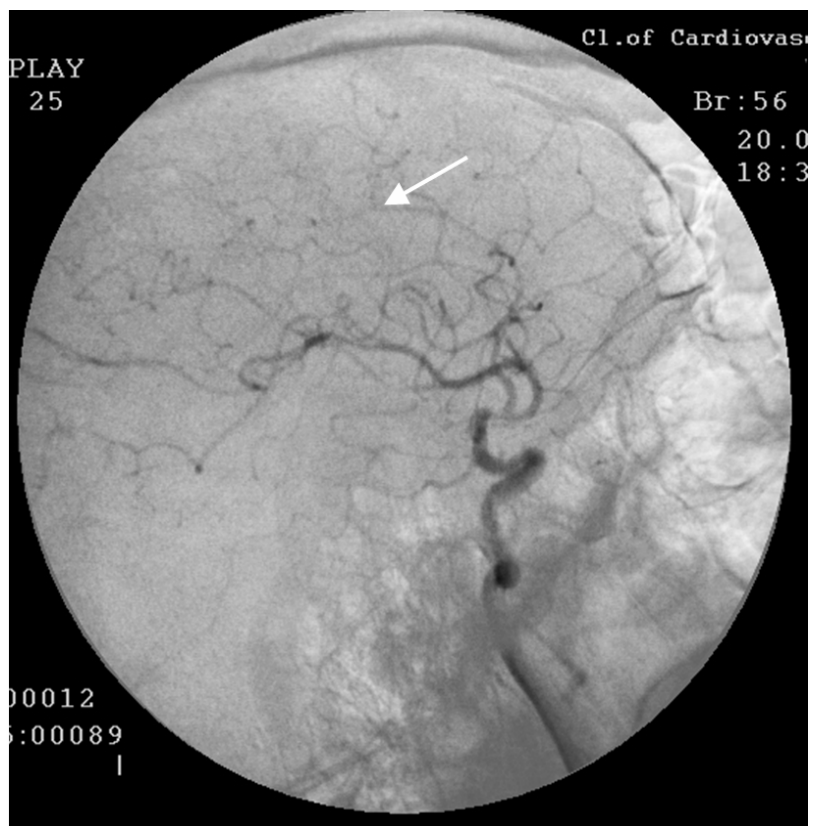

Figure 16. The same patient G.: left-sided carotid MUGA (lateral projection). BEFORE THE OPERATION: occlusion of the left anterior cerebral artery.

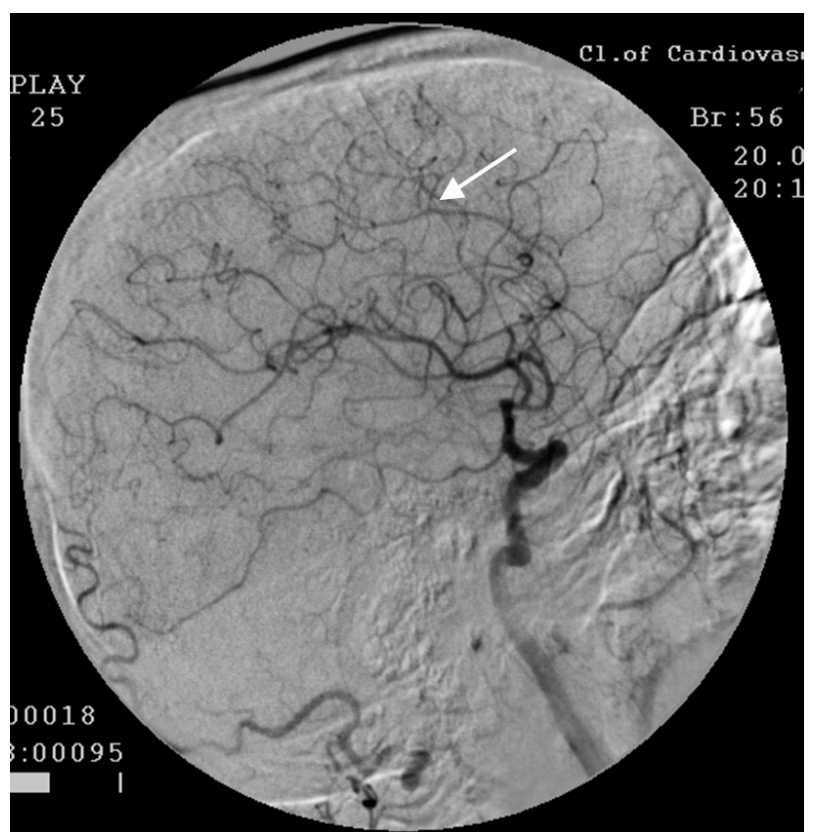

Figure 17. The same patient G.: left-sided carotid MUGA (lateral projection). AFTER THE OPERATION: restoration of the left anterior cerebral artery, marked collateral revascularization.

In the early postoperative period, the patient developed re-embolization of thrombotic masses, this time in the middle third of the right middle cerebral artery, as a result of which he died.

The development of this outcome cannot be considered as related to the treatment, and therefore the patient is not included in the statistics.

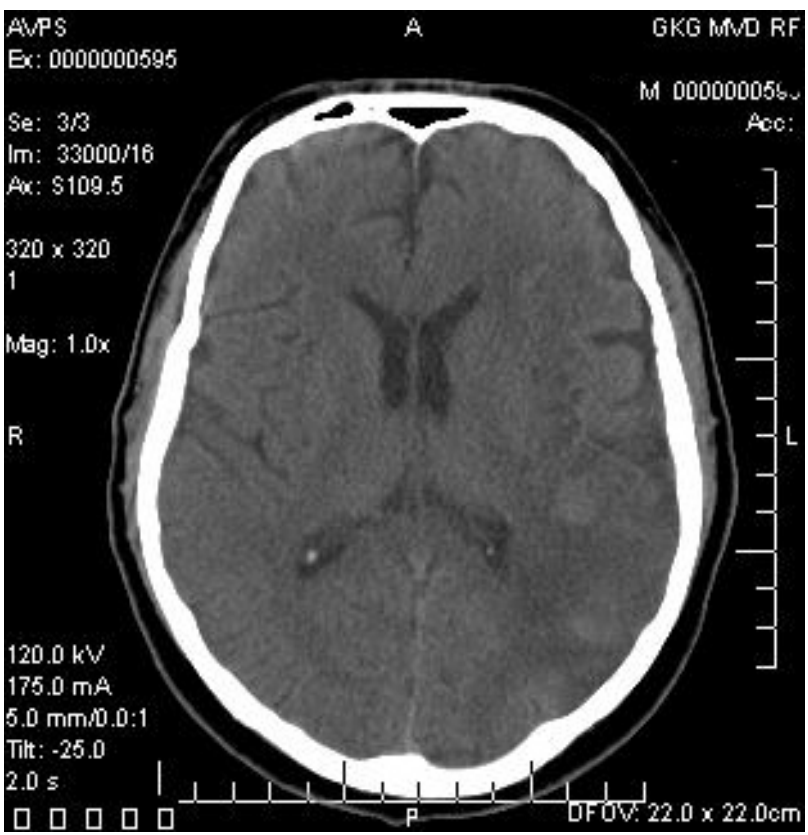

Figure 18. The same patient G.: CT of the brain. 1 YEAR AFTER LASER REVASCULARIZATION: regression of the postischemic cyst with the symptoms of the structure of the brain tissue restoration.

\subsection{Control Group}

\subsubsection{Immediate Results}

Immediately after the treatment the patients did not demonstrate any negative dynamics; there was a positive trend manifested in reduced mental disorders and improved physical activity.

\subsubsection{Results According to SG and REG Data}

According to SG, partial improvement of blood flow in the hemispheres of the brain was observed in 16 (66.67\%) cases. It was not stable enough, and during the subsequent follow-up in 12 - 24 months there was a partial regression.

According to REG, partial improvement of pulse blood volume in the carotid and vertebrobasilar basin was observed in 18 (75.00\%) cases. It was not stable enough, and during the subsequent follow-up in 12 months there was a regression.

\subsubsection{Results According to $\mathrm{CT}$ and MRI Data}

According to CT and MRI data, there was no significant reduction in the size of the postischemic cyst in any case in the first $12-24$ months after treatment.

\subsubsection{Clinical Results}

According to IB, the treated patients showed the following clinical outcome in 12 - 24 months after the beginning of the treatment:

- a good clinical outcome was not obtained in any case; 
- a satisfactory clinical outcome was not obtained in any case;

- a relatively satisfactory clinical outcome was obtained in 4 (16.67\%) cases;

- a relatively positive clinical outcome was obtained in 20 (83.33\%) cases;

No negative result was obtained after the treatment. Statistical analysis of the data is presented in Table 1.

7 Control Group patients, whose severity of dementia and cognitive impairment could have been determined before the treatment, had the following positive trend in 12 - 24 months:

- Reduction of the severity of dementia to CDR-1 with initial CDR-2, restoration of cognitive function to 21 26 MMSE points were obtained in 1 (14.29\%) case.

- Reduction of the severity of dementia to CDR-2 with initial CDR-3, restoration of cognitive function to 17 20 MMSE points were obtained in 1 (14.29\%) case.

- Preservation of the severity of dementia and cognitive impairment at their initial level was obtained in 5 (71.43\%) cases.

\section{DISCUSSION}

In patients who have had small or medium-sized focal ischemic strokes, the severity of mental and motor disorders does not always have a direct relationship to the size of the ischemic focus; it is often associated with the localization of the ischemic injury, the duration of ischemia, as well as with the prevalence of atherosclerosis leading to hemodynamic instability both in the stroke area and in other intracranial arterial basins [13].

In patients who have had an extensive ischemic stroke, it all proceeds much harder. The ischemic area includes various regions of the brain, which leads to a marked neurological deficit, a more serious condition, more severe symptoms and concomitant pathological processes $[1,5]$. Patients tend to develop severe confusion of consciousness, impaired speech with the development of sensory-motor aphasia, gross motor dysfunction [2,35]. Subsequently, it is not always possible to determine the severity of dementia and the degree of initial cognitive impairment $[29,30]$, and the maximum that can be defined in such patients is IB [28,31,35]. If the patient is unable to answer a question or perform a particular command, it does not mean that these are the signs of dementia and cognitive impairment. Possibly, it is not advisable to perform CDR determination or MMSE testing in these patients. We initially conducted this examination only in those patients who were able to fulfill it. However, the assessment of the severity of dementia and the severity of cognitive impairment may be performed after treatment and its positive results.

During the examination of cerebral blood flow and the identification of the causes of the stroke, it is necessary to examine all, both extracranial and intracranial, basins. Despite the widespread notion that atherosclerotic lesions of the extracranial arteries contribute to the development of cognitive impairment [17] and cause stroke, it is not always so in our opinion [13,36].

Atherosclerotic process is very slow. In some groups of patients, occlusions of one, two, and sometimes three extracranial branches do not lead to severe ischemia. Gradual stenosis of the large extracranial trunks stimulates natural angiogenesis and promotes natural collateral blood supply from other arterial basins, which leads to restructuring of cerebral hemodynamics. All these processes take place gradually and are often asymptomatic, and as a result, the patients are compensated for quite a long time [13,20].

In our research, all treated patients with a massive stroke had an intracranial or a mixed type of atherosclerotic disease; an extracranial lesion in pure form has not been revealed.

The size and location of the postischemic focus depend on the peculiarities of the angioarchitectonics of the brain in each patient, the prevalence, development and participation of a certain intracranial arterial basin in the blood supply of the brain, as well as the prevalence of atherosclerotic lesions [13,34]. Obviously, by analogy with the blood supply to the myocardium, it is necessary to consider the initially more developed and more significant intracranial arterial basins and to divide the brain blood supply into the front, middle or rear type.

With the development of a stroke, a separate group is formed by patients with atheromatous disintegration of atherosclerotic plaques of extracranial vessels [16]. In this case, a stroke is caused by embolism of thrombus or tissues from the damaged atherosclerotic plaque to the intracranial, also stenosed, arterial branches, but these patients are not the subject of this research.

Extracranial lesions are easily and successfully amenable to surgical and traditional interventional treatment $[17,20]$, but the restoration of blood flow in the major arteries of the neck does not always solve the problem of brain revascularization with an extensive ischemic stroke $[13,35]$. The development of a macrofocal stroke is frequently associated with occlusion or subtotal stenosis of several intracranial branches. With a lesion of this kind, it is necessary to conduct restoration of each of the affected basins [31]. In this regard, the transcatheter method of laser revascularization, allowing work on different vessels of a small diameter, has certain advantages [13,26, 27].

With the development of a stroke, the ischemic area is not a homogeneous conglomerate of cells. Naturally, performing the revascularization of the ischemic hemisphere, we cannot fully restore the dead areas of tissue in the 
infarct core. However, the restoration of blood flow in the area penumbra with bordering ischemia can lead to the improvement and even the restoration of the functions of this cerebral tissue, which in turn helps to restore the general functions of the affected hemisphere [13,35]. The improvement of blood supply to the affected atherosclerotic contralateral hemisphere, on the one hand, helps to improve its functionality, and on the other hand, contributes to the contralateral collateral revascularization and functional restoration of the hemisphere which has developed the stroke $[13,31,35]$. All this leads to an overall functional recovery of the brain.

Considering the mechanism of action of the method it must be noted that sighting high energy laser impact allows to destroy atherosclerotic tissue and to restore the patency and lumen of atherosclerotic vessels without affecting the vascular wall. The size of the decay products of atherosclerotic tissue is very small, it is composed of particles of 2 - 6 micrometers [31-34], which does not require distal protection. Low-energy laser irradiation, on the one hand, stimulates the natural, physiological angiogenesis and causes collateral and capillary revascularization $[13,35,37,38]$. On the other hand, due to the sufficient depth of penetration of the laser energy, it has an effect on ischemic brain tissue by stimulating metabolic processes in neurons [31,35,38]. The subsequent gradual decrease in the size of the post-ischemic cyst and an increase in the tissue mass of the affected hemisphere may indicate the development of regenerative processes $[35,39,40]$. This hypothesis is indirectly confirmed by an increasing number of experimental and clinical studies that prove the possibility of regenerative processes in the unaffected and ischemic brain tissue [30,41].

On the contrary, the use of conservative treatment for extensive ischemic strokes does not allow to achieve marked and persistent cerebral revascularization. The resulting therapeutic effect is mainly due to the partial improvement of metabolic processes in the ischemic area, but it is often not enough for the functional recovery of the brain.

The method of transcatheter laser revascularization of cerebral vessels is a physiological, effective and lowinvasive treatment method for patients who have had an extensive, spreading to different regions of the brain ischemic stroke. The method allows to restore the patency and lumen of vessels of various diameter, and it simultaneously causes collateral and capillary revascularization both of the ischemic area and of the tissue located nearby as well as promotes reparative processes in the brain tissue, which in turn helps to functionally restore the brain.

The effect is maintained for a long time, it causes regression of mental, intellectual and motor disorders, promotes regression of post-stroke dementia and significantly improves the patients' quality of life. It all makes the method proposed noticeably different from the conservative methods of treatment.

\section{REFERENCES}

[1] Crozier, S. (2012) Withdrawing and withholding treatments in acute severe stroke patients in the elderly. $L a$ Revue du Praticien , 62, 1243-1245. http://www.ncbi.nlm.nih.gov/pubmed/23272475

[2] Abou-Chebl, A. (2013) Management of acute ischemic stroke. Current Cardiology Reports, 15, 348-354. http://www.ncbi.nlm.nih.gov/pubmed/23420444 doi:10.1007/s11886-013-0348-4

[3] Gillum, R.F., Kwagyan, J. and Obisesan, Th.O. (2011) Ethnic and geographic variation in stroke mortality trends. Stroke, 42, 3294-3296.

http://www.ncbi.nlm.nih.gov/pubmed/21940976 doi:10.1161/STROKEAHA.111.625343

[4] Pendlebury, S.T., Wadling, S., Silver, L.E. and Rothwell, P.M. (2011) Transient cognitive impairment in TIA and minor stroke. Stroke, 42, 3116-3121. doi:10.1161/STROKEAHA.111.621490

[5] Pasi, M., Poggesi, A., Salvadori, E. and Pantoni, L. (2012) Post-stroke dementia and cognitive impairment. Front Neurol Neurosci, 30, 65-69.

http://www.ncbi.nlm.nih.gov/pubmed/22377866 doi:10.1159/000333412

[6] ElAli, A., Doeppner, T.R. and Hermann, D.M. (2011) Increased blood-brain barrier permeability and brain edema after focal cerebral ischemia induced by hyperlipidemia: Role of lipid peroxidation and Calpain-1/2, matrix Metalloproteinase-2/9, and Rho A overactivation. Stroke, 42, 3238-3244.

http://www.ncbi.nlm.nih.gov/pubmed/21836084 doi:10.1161/STROKEAHA.111.615559

[7] Frölich, A.M., Psychogios, N.M., Klotz, E., et al. (2012) Angiographic reconstructions from whole-brain perfusion CT for the detection of large vessel occlusion in acute stroke. Stroke, 43, 97-102. doi:10.1161/STROKEAHA.111.630954

[8] Tu, H.T., Campbell, B.C., Christensen, S., et al. (2013) Worse stroke outcome in atrial fibrillation is explained by more severe hypoperfusion, infarct growth, and hemorrhagic transformation. International Journal of Stroke, $\mathbf{8}$, 12. http://www.ncbi.nlm.nih.gov/pubmed/23489996

[9] Moustafa, R.R., Momjian-Mayor, I., Simon Jones, P., Morbelli, S., Day, D.J., Aigbirhio, F.I., Fryer, T.D., Warburton, E.A. and Baron, J.C. (2011) Microembolism versus hemodynamic impairment in rosary-like deep watershed infarcts: A combined positron emission tomography and transcranial doppler study. Stroke, 42, 3138-3143. doi:10.1161/STROKEAHA.111.616334

[10] Polak, J.F., Pencina, M.J., O’Leary, D.H. and D’Agostino, R.B. (2011) Common carotid artery intima-media thickness progression as a predictor of stroke in multi-ethnic study of atherosclerosis. Stroke, 42, 3017-3021. http://www.ncbi.nlm.nih.gov/pubmed/?term=Polak+JF\% 2C+Pencina+MJ\%2C+O'Leary+DH\%2C+D'Agostino+R 


\section{B doi:10.1161/STROKEAHA.111.625186}

[11] Liebeskind, D.S. (2005) Collaterals in acute stroke: Beyond the clot. Neuroimaging Clinics of North America, 15, 553-573.

http://www.ncbi.nlm.nih.gov/pubmed/?term=Collaterals+ in+acute+stroke\%3A+beyond+the+clot doi:10.1016/j.nic.2005.08.012

[12] Zhulev N.M., Pustozertsev, V.G. and Zhulev, S.N. (2002) Cerebrovascular diseases. BINOM, Moscow. http://www.combook.ru/product/158808/

[13] Maksimovich, I.V. (2012) Transcatheter treatment of atherosclerotic lesions of the brain complicated by vascular dementia development. World Journal of Neuroscience, 2, 200-209.

http://www.scirp.org/journal/PaperInformation.aspx?pape

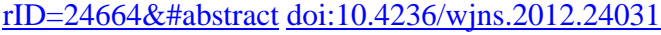

[14] Albers, G.W. and Olivot, J.M. (2007) Intravenous alteplase for ischaemic stroke. Lancet, 369, 249-250. http://www.ncbi.nlm.nih.gov/pubmed/17258646 doi:10.1016/S0140-6736(07)60120-2

[15] Hacke, W., Kaste, M., Bluhmki, E., et al. (2008) Thrombolysis with alteplase 3 to 4.5 hours after acute ischemic stroke. The New England Journal of Medicine, 359, 1317-1329.

http://www.ncbi.nlm.nih.gov/pubmed/18815396

[16] Liu, R., Yuan, H., Yuan, F. and Yang, S.H. (2012) Neuroprotection targeting ischemic penumbra and beyond for the treatment of ischemic stroke. Journal of Neurology Research, 34, 331-337. http://www.ncbi.nlm.nih.gov/pubmed/22643076

[17] Takaiwa, A., Kuwayama, N., Akioka, N., Kurosaki, K., et al. (2013) Effect of carotid endarterectomy on cognitive function in patients with asymptomatic carotid artery stenosis. Acta Neurochirurgica, 155, 627-633. http://link.springer.com/article/10.1007/s00701-013-1625 $\underline{-0}$

[18] Silver, F.L., Mackey, A., Clark, W.M., Brooks, W., Timaran, C.H., Chiu, D., Goldstein, L.D., Meschia, J.F., Ferguson, R.D., Moore, W.S., Howard, G. and Brott, T.G. (2011) Safety of stenting and endarterectomy by symptomatic status in the Carotid Revascularization Endarterectomy versus Stenting Trial (CREST). Stroke, 42, 675680. doi:10.1161/STROKEAHA.110.610212

[19] Muroi, C., Khan, N., Bellut, D., Fujioka, M. and Yonekawa, Y. (2011) Extracranial-intracranial bypass in atherosclerotic cerebrovascular disease: Report of a single centre experience. British Journal of Neurosurgery, 25, 357-362. http://www.ncbi.nlm.nih.gov/pubmed/21501047 doi:10.3109/02688697.2010.551673

[20] Papanagiotou, P., Roth, C., Walter, S., Behnke, S., Grunwald, L.Q., Viera, J., Politi, M., Körner, H., Kostopoulos, P., Haass, A., Fassbender, K. and Reith, W. (2011) Carotid artery stenting in acute stroke. Journal of the American College of Cardiology, 58, 2363-2369. http://content.onlinejacc.org/article.aspx?articleid=11478 02 doi:10.1016/j.jacc.2011.08.044

[21] Rohde, S., Seckinger, J., Hähnel, C., et al. (2013) Stent design lowers angiographic but not clinical adverse events in stenting of symptomatic intracranial stenosis-
Results of a single center study with 100 consecutive patients. International Journal of Stroke, 8, 87-94. http://onlinelibrary.wiley.com/doi/10.1111/j.1747-4949.2 $\underline{011.00715 . x / a b s t r a c t}$

[22] Fjetland, L., Roy, S., Kurz, K.D., et al. (2012) Endovascular acute stroke treatment performed by vascular interventional radiologists: Is it safe and efficacious? CardioVascular and Interventional Radiology, 35, 1029-1035. http://link.springer.com/article/10.1007/s00270-012-0438 $\underline{-5}$

[23] Lee, J.S., Hong, J.M., Lee, S.J., et al. (2013) The combined use of mechanical thrombectomy devices is feasible for treating acute carotid terminus occlusion. Acta Neurochirurgica, 155, 635-641. http://link.springer.com/article/10.1007/s00701-013-1649 $\underline{-5}$

[24] Ciccone, A., Valvassori, L., Nichelatti, M., et al. (2013) Endovascular treatment for acute ischemic stroke. The New England Journal of Medicine, 7, 904-913. http://www.ncbi.nlm.nih.gov/pubmed/23387822

[25] Abou-Chebl, A. (2013) Intra-arterial therapy for acute ischemic stroke. CardioVascular and Interventional $\mathrm{Ra}$ diology, 1, 100-108. http://www.karger.com/Article/FullText/346769

[26] Maksimovich, I.V. (2006) Method for carrying out transluminal laser-induced brain revascularization in atherosclerotic injury cases. RF Patent No. 2297861. http://worldwide.espacenet.com/publicationDetails/biblio ?II $=3 \& N D=3 \&$ adjacent $=$ true\&locale $=$ en_EP\&FT $=D \& d a t$ $\mathrm{e}=20070427 \& \mathrm{CC}=\mathrm{RU} \& \mathrm{NR}=2297861 \mathrm{C} 1 \& \mathrm{KC}=\mathrm{C} 1$

[27] Maksimovich, I.V. (2006) Method of transluminal laser revascularization of cerebral blood vessels having atherosclerotic lesions. US Patent No. 7490612.

http://www.patentlens.net/patentlens/patents.html?patnu ms=US 7490612\&returnTo=patentnumber.html\%3Fquer y\%3D\%2528US_7490612\%2Bin\%2Bpublication_numbe r\%2529

[28] Mahoney, F.I. and Barthel, D.M. (1965) Functional evaluation: The barthel index. Maryland State Medical Journal, 14, 61-65. http://www.ncbi.nlm.nih.gov/pubmed/14258950

[29] Morris, J.C. (1993) The Clinical Dementia Rating (CDR): Current version and scoring rules. Neurology, 43, 24122414. http://www.ncbi.nlm.nih.gov/pubmed/8232972 doi:10.1212/WNL.43.11.2412-a

[30] Folstein, M.F., Folstein, S.E. and McHugh, P.R. (1975) "Mini-mental state". A practical method for grading the cognitive state of patients for the clinician. Journal of Psychiatric Research, 12, 189-198. http://www.ncbi.nlm.nih.gov/pubmed/1202204 doi:10.1016/0022-3956(75)90026-6

[31] Maksimovich, I.V. (2010) Transluminal Laser revascularization of cerebral blood vessels in the treatment of ischemic stroke. Journal of the American College of Cardiology, 56, B48-B49.

http://www.sciencedirect.com/science/article/pii/S073510 9710030809

[32] Deviatkov, N.D., Rabkin, I.Kh., Maksimovich, I.V., Rogov, R.A. and Aleinikov, V.S. (1986) Use of copper- 
vapor laser radiation for the evaporation of atherosclerotic lesions of the major arteries in vitro. Surgery, $\mathbf{4}$, 116-121. http://www.ncbi.nlm.nih.gov/pubmed/3713043

[33] Petrovskiy, B.V., Deviatkov, N.D., Rabkin, I.Kh., Maksimovich, I.V. and Rogov, K.A. (1986) Destruction of arteriosclerotic lesions of human cadaveric arteries by laser irradiation with copper vapors. Surgery, 5, 112-116. http://www.ncbi.nlm.nih.gov/pubmed/3723942

[34] Kuleshov, E.V. and Maksimovich, I.V. (1994) Endovascular surgery in patients over 65 with disseminated atherosclerosis of the vessels of the pelvis and lower extremities. Vestnik Khirurgii Imeni I. I. Grekova, 152, 27-30. http://www.ncbi.nlm.nih.gov/pubmed/7701734

[35] Maksimovich, I.V. (2004) Transljuminal laser angioplasty in treatment of ischemic lesions of a brain. M.D. Dissertation, Russian University of Friendship of the People, Moscow. http://disseng.com/page/order/id/206426.html

[36] Deramecourt, V., Slade, J.Y., Oakley, A., Perry, R.H., Ince, P.G., Maurage, C.A. and Kalaria, R.N. (2012) Staging and natural history of cerebrovascular pathology in dementia. Neurology, 78, 1043-1050. http://www.ncbi.nlm.nih.gov/pubmed/22377814 doi:10.1212/WNL.0b013e31824e8e7f

[37] Chizhov, G.K., Kovalskaia, N.I. and Kozlov V.I. (1991) The effect of helium-neon laser radiation on the energy metabolic indices of the myocardium. Bulletin of Experimental Biology and Medicine, 111, 302-305.

http://www.ncbi.nlm.nih.gov/pubmed/2054512 doi:10.1007/BF00840904

[38] Kozlov, V.I. and Azizov, G.A. (2007) Pathophysiological characteristics of microcirculatory disorders in chronic arterial ischaemia of lower limbs. Angiology and Vascular Surgery, 13, 17-23. http://www.ncbi.nlm.nih.gov/pubmed/17679971

[39] Moskvin, S.V. (2008) System analysis of efficiency in controlling biological systems with low-energy laser radiation. Thesis for Degree of Doctor of Biological Sciences, City of Tula.

http://www.dissers.info/disser_323120.html

[40] Starck, T., Nissilä, J., Aunio, A., Abou-Elseoud, A., Remes, J., Nikkinen, J., Timonen, M., Takala, T., Tervonen, O. and Kiviniemi, V. (2012) Stimulating brain tissue with bright light alters functional connectivity in brain at the resting state. World Journal of Neuroscience, 2, 81-90. http://www.scirp.org/journal/PaperInformation.aspx?pape $\underline{\text { rID }=19417 \text { \#abstract }}$

[41] Heinrich, C., Blum, R., Gascón, S., et al. (2010) Directing astroglia from the cerebral cortex into subtype specific functional neurons. PLOS Biology, 8, e1000373. http://www.ncbi.nlm.nih.gov/pubmed/20502524 